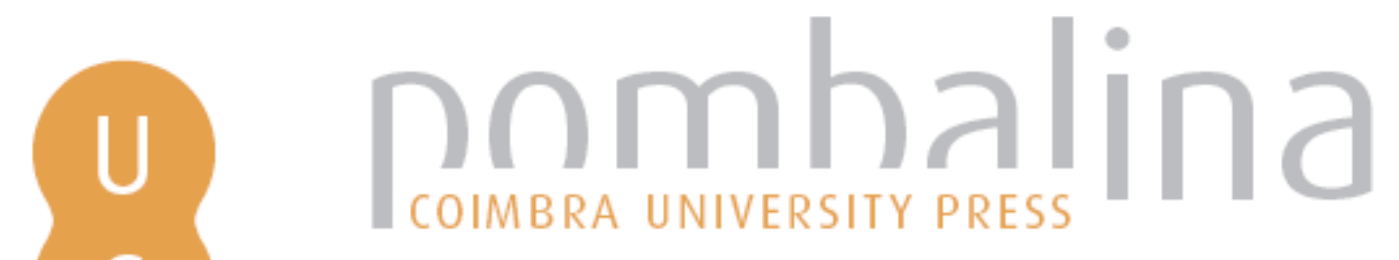

\title{
Educação, ciência e sociedade
}

Autor(es): Soares, Mário

Publicado por: Imprensa da Universidade de Coimbra; Gradiva

URL

persistente: $\quad$ URI:http://hdl.handle.net/10316.2/32714

DOI: $\quad$ DOI:http://dx.doi.org/10.14195/978-989-26-0389-6_25

Accessed : $\quad$ 26-Apr-2023 09:22:27

A navegação consulta e descarregamento dos títulos inseridos nas Bibliotecas Digitais UC Digitalis, UC Pombalina e UC Impactum, pressupõem a aceitação plena e sem reservas dos Termos e Condições de Uso destas Bibliotecas Digitais, disponíveis em https://digitalis.uc.pt/pt-pt/termos.

Conforme exposto nos referidos Termos e Condições de Uso, o descarregamento de títulos de acesso restrito requer uma licença válida de autorização devendo o utilizador aceder ao(s) documento(s) a partir de um endereço de IP da instituição detentora da supramencionada licença.

Ao utilizador é apenas permitido o descarregamento para uso pessoal, pelo que o emprego do(s) título(s) descarregado(s) para outro fim, designadamente comercial, carece de autorização do respetivo autor ou editor da obra.

Na medida em que todas as obras da UC Digitalis se encontram protegidas pelo Código do Direito de Autor e Direitos Conexos e demais legislação aplicável, toda a cópia, parcial ou total, deste documento, nos casos em que é legalmente admitida, deverá conter ou fazer-se acompanhar por este aviso.

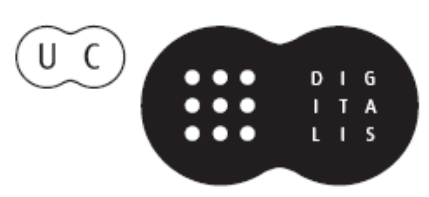


C I E N C I A I B E R T A

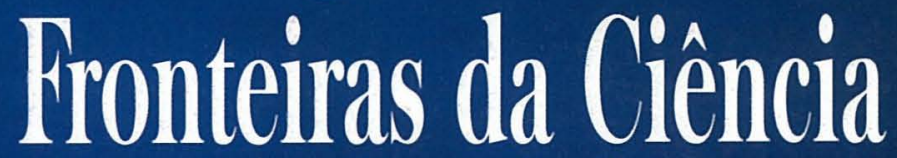

Desenvolvimentos Recentes - Desafios Futuros

RUI FAUSTO • CARLOS FIOLHAIS • JOÃO FILPE QUURRÓ

Coordenadores



gradiva - Imprensa da Universidade de Coimbra 
(Página deixada propositadamente em branco) 


\section{RUI FAUSTO, CARLOS FIOLHAIS JOÃO FILIPE QUEIRÓ \\ Coordenadores}
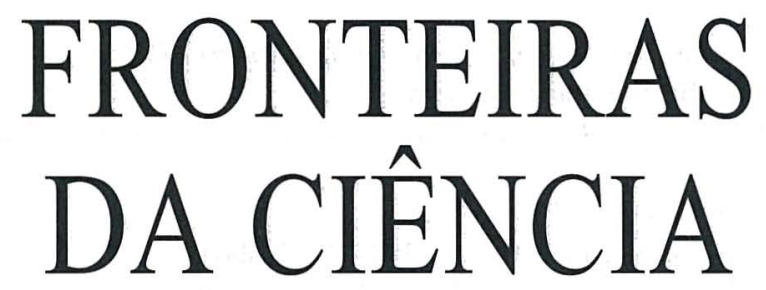

Desenvolvimentos Recentes Desafios Futuros 
(C) Gradiva - Publicações, L. da / Imprensa da Universidade de Coimbra, 2003 Coordenação editorial: Rui Fausto, Carlos Fiolhais e João Filipe Queiró Tradução: Jean Burrows, Vivien Burrows, Rui Fausto, Carlos Fiolhais e João Filipe Queiró

Revisão do texto: Isabel Pedrome

Capa: António Barros [Imprensa da Universidade. Coimbra], sobre imagem de «Águas Vivas», escultura de Silvestre Pestana, 2001

Foto: António Alves; Infografia: ESTÍMULUS [design]; Cortesia: Galeria Alvarez-Arte Contemporânea

Paginação: António Resende e Paula Isabel Jorge

Impressão e acabamento: G.C. - Gráfica de Coimbra, L. ${ }^{d a}$

Reservados os direitos para Portugal por:

Gradiva - Publicações, L. ${ }^{\text {da }}$ e Imprensa da Universidade de Coimbra

Gradiva - Publicações, L.da

Rua Almeida e Sousa, 21, r/c, esq.•1399-041 Lisboa

Telefs. $213974067 / 8 \cdot 213971357 \cdot 213953470$

Fax $213953471 \cdot$ Email: gradiva@ip.pt

URL: http://www.gradiva.pt

Imprensa da Universidade de Coimbra

Rua Antero de Quental, 195 • 3000-033 Coimbra

Telefs. 351239853110

Fax 3512398531 19・e-mail: fjrpress@ci.uc.pt

URL: http://www.imp.uc.pt

ISBN: 972-662-923-3

1." edição: Agosto de 2003

Depósito legal n. ${ }^{\circ} 199$ 463/2003 
Fundação Mário Soares

Lisboa

\section{Educação, ciência e sociedade}

A minha especialidade não é a ciência e não me considero preparado para dizer algo de novo acerca dos seus desenvolvimentos recentes, das suas novas fronteiras e dos desafios futuros que se lhe deparam.

A qualidade e a competência das personalidades que intervieram sobre os diversos temas deste colóquio são indiscutíveis. Mesmo as personalidades que participaram na última sessão - cujos temas, história e literatura, se podem considerar mais próximos da minha formação e das minhas preocupações - são cientistas, investigadores e professores universitários com uma preparação especializada sobre os temas em debate.

O meu caso é diferente. Tenho uma formação mais ou menos literária e mais ou menos jurídica. E digo «mais ou menos» porque, em ambos os casos, nunca desenvolvi e completei essa preparação. Tentei enveredar pela história, mas por circunstâncias diversas, não me foi possível seguir por esse caminho. Também fiz o curso de Direito e cheguei a ser advogado - ou, melhor, um prático do Direito - mas nunca desenvolvi e consolidei a minha formação jurídica.

Aliás, acabei por ser desviado para a política por circunstâncias em boa parte estranhas à minha vontade. Passei, por isso, uma vida inteira ocupado com problemas de natureza diferente daqueles que têm sido abordados neste colóquio. Digamos que não tive a oportunidade para me informar suficientemente, nem a disponibilidade para ler, nem o tempo necessário para reflectir sobre eles. 
Em todo o caso, o tema sobre o qual me pediram que falasse - educação, ciência e sociedade - é muito interessante e está mais próximo daquilo que são as minhas preocupações, ainda que a minha preparação em matéria de educação e de ciência também seja insuficiente e limitada.

Alguns talvez se recordem de que, no início da década de 90, manifestei publicamente a minha preocupação em relação ao problema da ciência. Era, evidentemente, uma preocupação de carácter genérico, na medida em que estava - e continuo a estar - convencido de que o desenvolvimento da cultura e da investigação científica são indispensáveis para impulsionar e garantir o desenvolvimento global do país. Foi por isso que, enquanto Presidente da República, patrocinei e participei em duas iniciativas científicas de alguma importância, no princípio dos anos 90 . A primeira foi uma conferência intitulada "A Ciência em Portugal», que teve lugar em Bruxelas, no âmbito da Europália 91, e que deu origem a alguma polémica. A segunda foi uma série de conferências e colóquios designada «A Ciência da Cultura» por mim organizada em 1992, e que depois deu origem a um livro que, julgo, ainda hoje mantém grande actualidade.

$\mathrm{Na}$ conferência sobre a ciência em Portugal, realizada no quadro da Europália 91, tratou-se fundamentalmente de fazer o inventário, o ponto da situação do estado de desenvolvimento da ciência em Portugal. A Europália 91 era, aliás, uma espécie de montra para estrangeiros, organizada em Bruxelas, com o objectivo de mostrar o que eram a história, a literatura, a arte, a cultura e a ciência em Portugal. Foram realizadas exposições notáveis, numa das quais, aliás, estiveram patentes alguns instrumentos científicos do século XVIII conservados na Universidade de Coimbra. Foi a partir dessa exposição que foi publicado um livro muito interessante e organizado o colóquio destinado a fazer um inventário sobre a situação da ciência no nosso país. Presidi a esse colóquio, ouvi o que nele se disse e fiz uma intervenção sobre um ponto muito específico.

O ponto de partida da reflexão que então se levou a cabo foi a constatação de que a educação e investigação científicas são indispensáveis ao desenvolvimento global de um país e de uma sociedade aberta à modernidade. Foi, aliás, estabelecida uma ligação - fundamental, do meu ponto de vista - entre educação cívica e educação científica, na medida em que liberdade, democracia e cidadania são essenciais ao desenvolvimento da ciência. A par da educação, é fundamental desenvolver o espírito crítico e o exercício da liberdade de opinião, do mesmo modo que o rigor experimental e a liberdade de investigação, essenciais ao trabalho de verificação de hipóteses por parte dos cientistas. 
Sabemos que Portugal foi grande nos séculos XV e XVI, quando estava na vanguarda da ciência náutica e das tecnologias de navegação oceânica, algumas delas inventadas por portugueses. Portugal conseguiu, por esse facto, descobrir o caminho marítimo para a Índia, navegar em todos os oceanos e desempenhar um importante papel no grande encontro de culturas que se verificou nos séculos XV e XVI. Foi a partir de então que o mundo começou a tornar-se um só, que o fenómeno da globalização começou a manifestar-se, a partir desse grande encontro de culturas. Portugal foi capaz de olhar para o que era novo e diferente com aquilo a que Duarte Pacheco Pereira chamou o saber de experiência feito. Perante um mundo estranho e as realidades completamente novas que se thes deparavam, os portugueses foram capazes de assumir uma atitude de curiosidade, de desenvolver o espírito crítico e de reflectir sobre essas novas realidades, o que lhes permitiu compreender e divulgar, de forma notável, aquilo que tinha sido visto. E tudo isto teve grande repercussão na Europa desse tempo. Sabemos que muitos cientistas célebres em todo o mundo no século XVIII, leram textos escritos por portugueses, tiveram conhecimento das estranhas realidades de outros continentes através, por exemplo, dos roteiros de D. João de Castro, dos textos de Garcia de Orta, dos relatos de Fernão Mendes Pinto, para só citar algumas das contribuições mais extraordinárias para a ciência da época dadas por autores portugueses.

Desde então, porém, Portugal entrou num período de dois séculos de decadência. E quando nos interrogamos sobre as razões dessa decadência - e desde o século XIX que essa interrogação é feita de forma sistemática - acabamos sempre por deparar com a explicação proposta por Antero de Quental nas célebres Conferências do Casino. As causas da decadência de Portugal foram, tal como Antero as apresentou, a intolerância religiosa e, portanto, a recusa do espírito crítico e da liberdade de opinião; a expulsão dos judeus e, portanto, da maioria daqueles que melhor dominavam a arte de marear e as ciências do tempo, além de serem os que mantinham as mais intensas relações com o exterior; e o absolutismo do poder real, que esmagou aquilo a que, recorrendo à linguagem actual, designaríamos por «sociedade civil».

Num dos mais belos ensaios que escreveu, António Sérgio salienta, precisamente, que o desenvolvimento da ciência dos portugueses do século XVI teria levado em linha recta ao aparecimento de homens como Espinoza. Mas Espinoza, apesar de ser filho de portugueses e de conhecer Portugal, não é um filósofo português porque a sua família foi expulsa e foi viver para a Holanda, onde, aliás, o filósofo também seria alvo de perseguições. E foi exactamente por causa dessa intolerância - dessa 
recusa do espírito crítico, do livre exame e do espírito científico - que Portugal se transformou naquilo a que o Cavaleiro de Oliveira, um estrangeirado e herético do século XVIII, chamaria «o reino cadaveroso», ou seja, o reino como um cadáver.

Talvez seja exagerada a expressão - à qual, aliás, António Sérgio muitas vezes se refere. Mas a verdade é que - após um período de recuperação, no século XIX, em consequência da revolução liberal e do espírito de liberdade que esta insuflou no país - o século XX também viria a ser marcado por um longo período «cadaveroso», um período negro da nossa história, em que o espírito crítico passou a ser policiado, a liberdade de opinião voltou a ser reprimida e a inteligência foi de novo perseguida. Dezenas de professores e de investigadores notáveis foram expulsos das universidades ou constrangidos a abandonar o ensino público durante o regime do Estado Novo. Foi um verdadeiro crime de lesa-pátria, que afectou sucessivas gerações de portugueses.

Com a revolução de 25 de Abril de 1974 e a liberdade por ela reconquistada começámos lentamente a recuperar desse período negro da nossa história contemporânea. Não surgiram imediatamente as obras de arte que se esperava que estivessem guardadas nas gavetas porque tinha faltado $o$ estímulo para as realizar, tal como tinham faltado as condições para produzir grandes obras científicas. Mas o certo é que, pouco mais de vinte anos passados, Portugal é um país novo e completamente diferente, em que as gerações mais jovens têm uma mentalidade e um modo de encarar as coisas inteiramente diverso do da minha geração. Podemos hoje dizer que foi conseguida a mais importante de todas as revoluções, que é, como dizia António Sérgio, a revolução das mentalidades. No país livre e democrático em que vivemos, as pessoas discutem e já não podem conceber que não se discuta, as pessoas têm opiniões diferentes e confrontam-nas entre si, as pessoas criticam e contestam, mas respeitam as diferenças e as divergências. Tudo isto é extremamente estimulante e tem reflexos em múltiplos domínios - tanto no domínio da cultura em sentido lato, como no domínio da ciência como cultura.

Hoje, os cientistas portugueses são tão bons nas especialidades a que se dedicam como os seus homólogos estrangeiros. Muitos deles tiveram de se formar ou completar a sua formação em universidades estrangeiras, durante o período negro do Estado Novo. Eram, de certo modo, os novos «estrangeirados». A liberdade e a democracia reconquistadas tornaram, outra vez, o termo obsoleto. Mas, se a qualidade é boa, a quantidade de cientistas portugueses é ainda insuficiente. $\mathrm{O}$ seu peso e influência na sociedade portuguesa são ainda muito inferiores aos de outras comunidades científicas estrangeiras nos respectivos países, mesmo em 
países europeus com a dimensão do nosso, mas mais avançados. $\mathrm{Na}$ generalidade dos casos, os nossos centros de investigação não estão suficientemente bem equipados, embora haja, felizmente, excepções. Além disso, vivem demasiadamente fechados sobre si próprios e estão muito dependentes tanto do poder burocrático como do poder político - e, em matéria científica, não sei qual deles é o pior.

Tudo isto se constatou na conferência em Bruxelas a que já me referi. Na altura em que a conferência foi realizada, em 1991, o ministro então responsável pelo sector da ciência afirmou que Portugal tinha objectivos imediatos a alcançar e, portanto, a investigação científica tinha de ser orientada no sentido da subordinação a esses objectivos, segundo um critério que, naturalmente, só podia ser o dele ou do governo a que ele pertencia. E eu fiz uma intervenção para dizer exactamente o contrário, para contestar essa orientação. Disse, precisamente, que a investigação científica não podia ser condicionada por orientações políticas, que os cientistas deviam dispor de inteira liberdade para fazerem a investigação que correspondesse às suas próprias preocupações, independentemente da sua utilidade imediata em termos políticos e financeiros. Creio que a polémica foi interessante e estimulante, tanto para o ministro como para mim próprio. É, aliás, um tipo de polémica muito frequente nas comunidades científicas.

A partir da polémica gerada por essa conferência verificou-se um movimento de progressivo reforço da comunidade científica portuguesa. Foi a partir dessa altura, aliás, que a expressão "comunidade científica», pouco habitual no nosso país, passou a ser utilizada com mais frequência. A verdade é que era preciso dar voz à comunidade científica enquanto tal, reconhecer a necessidade de ela se auto-organizar para poder intervir com voz própria. As associações científicas das mais diversas naturezas que entretanto se foram criando têm sido, julgo eu, um importantíssimo factor de incremento da investigação e do desenvolvimento da ciência, no seu sentido mais genérico, em Portugal. O caminho percorrido desde então parece-me muito significativo. A ciência portuguesa avançou bastante nos últimos anos. Um dos participantes mais activos na conferência de Bruxelas, em 1991, foi precisamente o Professor Mariano Gago, que é hoje ministro da Ciência e da Tecnologia, e cujo trabalho tem sido importante e meritório.

A série de conferências e colóquios que também já referi, subordinada ao tema da ciência como cultura e promovida por mim em 1992, também se revestiu de alguma importância. De um modo geral, as pessoas tinham tendência para considerar a cultura como qualquer coisa de natureza literária e livresca e a ciência como qualquer coisa de natureza experimental. Por 
isso, dizer que a ciência também é cultura era, de certa forma, uma inovação. Um dos principais temas abordados foi justamente o do investimento que é necessário fazer na educação e, especialmente, na educação científica e nas novas tecnologias de informação. E esse investimento tem sido feito. Hoje podemos dizer que são já muito poucas as escolas, sejam elas do ensino básico ou do ensino secundário, em que as crianças portuguesas não têm contacto com essas pequenas máquinas chamadas computadores - coisa ainda muito difícil para nós, os mais velhos.

Ainda há poucos dias tive a oportunidade de falar com um dos mais importantes dirigentes europeus da Microsoft, que veio a Portugal e me disse uma coisa que me impressionou bastante e é muito relevante para nós, Portugueses. Comparativamente, a Microsoft vende, proporcionalmente, muito mais software para Portugal do que para Espanha. E o mesmo se passa com a venda de computadores. Portugal compra o dobro, enquanto a Espanha compra quatro a cinco vezes menos do que seria de esperar. E o dirigente da Microsoft considera que esse é um sintoma extremamente positivo para a empresa e é por isso que o mercado português lhes interessa bastante.

Mas, para além do investimento na educação - na formação contínua, pós-universitária e de pós-graduação —, na investigação científica — sem procurar orientar essa investigação segundo critérios de natureza política, que são sempre discutíveis - a série de conferências e colóquios de 1992 pôs o acento tónico na afirmação da ciência como cultura, como uma das formas de cultura. Ou seja, foi acentuada a necessidade de abordar os diferentes tipos de investigação científica de uma forma inter disciplinar, cruzando os diferentes saberes numa perspectiva integrada, que permita dar resposta a algumas questões e inquietações fundamentais do nosso tempo.

Daí derivam, aliás, vários problemas actuais muito interessantes e complexos, que estão na ordem do dia em todo o mundo e também em Portugal, como é o caso das relações entre a ciência e a ética. Até à explosão da primeira bomba atómica, em 1945, julgava-se que a ciência perseguia sempre objectivos benéficos e que dela nunca poderia vir mal ao mundo, antes pelo contrário, só podia vir o bem. Depois de Hiroshima constatou-se que afinal não era assim, que a ciência podia gerar fenómenos terríveis e podia ser altamente nociva para a humanidade, até ao ponto de, eventualmente, a poder destruir. Hoje, porém, com os desenvolvimentos da engenharia genética e outros desenvolvimentos científicos, a questão já não se põe apenas em relação à bomba atómica. Daí a importância de estabelecer relações cada vez mais estreitas entre ciência e ética, 
procurando saber em que medida as opções, em matéria de investigação científica, devem ser precedidas e integradas por princípios e valores de natureza ética.

Também as relações entre a ciência e a democracia me parecem óbvias. Tanto para uma como para outra a liberdade é absolutamente indispensável. É na liberdade que uma e outra assentam. Quando hoje nos interrogamos sobre as razões do colapso do sistema comunista a nível mundial, a primeira razão que surge, para além de outros motivos circunstanciais, é falta de liberdade individual, falta de respeito pelos direitos essenciais da pessoa humana. É que, precisamente, não havia liberdade nas sociedades comunistas e essa falta de liberdade foi fatal porque bloqueou o seu progresso. A liberdade de opinião e de crítica, a liberdade de dizer o contrário daquilo que está estabelecido e de pensar contra a corrente é fundamental para o progresso.

Bem mais complexas são as relações entre a ciência e a razão, tendo em conta, nomeadamente, a interrogação fundamental sobre se a razão é a única via de acesso ao conhecimento, como sustentava o iluminismo, ou se haverá outras formas de conhecimento para além das que a razão proporciona. Esta interrogação não tem apenas a ver com a questão apresentada por António Damásio no seu livro O Erro de Descartes, no qual se explica que as opções racionais são muitas vezes estimuladas pelas emoções, que assim influenciam e fundamentam a própria razão. A interrogação tem igualmente a ver com saber se não haverá outras formas de acesso ao conhecimento sem ser através da razão - como, por exemplo, através de experiências místicas e outras formas esotéricas.

Por mim, considero-me um racionalista militante. Fui educado de acordo com a filosofia das «luzes», do iluminismo. E fui um «seareiro», isto é, as personalidades que mais influenciaram a minha formação foram os homens da revista Seara Nova, como por exemplo Raul Proença, Jaime Cortesão e António Sérgio. Ora todas essas grandes figuras intelectuais tinham o racionalismo como base do seu pensamento e acção.

Mas, para além do racionalismo, persistem muitas dúvidas e interrogações que resultam dos próprios mistérios da natureza, que nos interpelam e para os quais não temos ainda - será que alguma vez teremos? - respostas adequadas. Mas não são só os mistérios do universo, são também os mistérios da própria condição humana e do nosso destino na Terra. A partir daí caminha-se numa outra direcção, que é a das convicções religiosas, porventura outra forma de acesso ao conhecimento - ou à revelação da verdade, como dizem as religiões ainda que nenhum de nós esteja propriamente em condições de dizer o que é a verdade, pelo menos em termos absolutos. Neste domínio, a minha 
capacidade de julgamento racional é muito limitada, é mínima, dada a minha estrutura mental. Por isso mesmo, digo que sou agnóstico, dado que, perante esses mistérios, não me sinto capaz de emitir juízos de valor e, muito menos ainda, de lhes dar respostas. As respostas dadas pelas diferentes religiões também não me satisfazem.

O mundo globalizado em que hoje vivemos é, como salienta Edgar Morin, extremamente complexo. Essa complexidade é tanto maior quanto mais amplo é o acesso directo às múltiplas formas de conhecimento que hoje estão ao nosso dispor. O que levanta, aliás, uma questão muito importante, que é saber se alguma vez seremos capazes de digerir o excesso de informação e de conhecimento que todos os dias surge em catadupas nos ecrãs dos nossos televisores e dos nossos computadores.

Como se poderá passar de uma fase de aquisição de saberes, múltiplos e indiscriminados, para uma fase de verdadeiro conhecimento, como forma de cultura que nos permita encontrar respostas para os problemas fundamentais da humanidade, quer na perspectiva do comportamento dos cidadãos entre si, enquanto seres humanos, quer na perspectiva das atitudes que devemos adoptar perante o universo que nos cerca? Esse é, a meu ver, o papel fundamental da educação. Só ela nos permitirá a libertação individual, mas também a libertação das nossas energias e potencialidades, conferindo-nos maior capacidade de resposta e de relacionamento entre as diferentes formas de conhecimento. É nessa perspectiva que considero indispensável investir numa cada vez melhor e mais ampla educação científica, a par da intensificação e desenvolvimento da educação cívica. Estas duas vias constituem - repito - dois pilares de uma mesma realidade, que tem por base a liberdade e a participação dos cidadãos, ou seja, a cidadania.

Não sou propriamente um entusiasta do estilo político do actual primeiro-ministro britânico, Tony Blair, mas estou de acordo com ele quando diz que dar igualdade de oportunidades a todos os jovens no acesso à educação deve ser a prioridade absoluta de qualquer governo que se reclame do socialismo democrático. Eu não diria «a prioridade», mas «uma das prioridades», na medida em que considero que a solidariedade é outra exigência tão importante como o acesso à educação, tendo sobretudo em conta a necessidade de subordinar o poder económico ao poder político - e este é, hoje, um dos problemas fundamentais das sociedades contemporâneas.

Tony Blair afirma que o máximo de igualdade a que se pode aspirar só pode ser alcançado proporcionando um máximo de igualdade de oportunidades a todos os jovens estudantes, independentemente dos meios materiais ao seu dispor, das fortunas dos pais e das classes sociais a que 
pertençam. Só assim será possível preparar verdadeiros cidadãos. Hoje em dia, a possibilidade de acesso às diversas formas de conhecimento é, ou deve ser, mais importante do que o dinheiro. A única fonte consistente de poder deve resultar da informação e do conhecimento.

A ciência é uma das pedras angulares da aventura humana sobre a Terra. Hoje, a ciência alerta-nos para os muitos perigos e desafios que nos espreitam no limiar de um novo século e de um novo milénio. As agressões ecológicas sobre o planeta são bem reais e cada vez mais preocupantes. Impressiona-me particularmente - e não apenas por dever de ofício - a degradação inimaginável dos oceanos (ou do oceano, visto que, na realidade, ele é um só) e a incapacidade da actual legislação internacional para regulamentar adequadamente e permitir uma gestão racional de um bem que é comum a toda a humanidade. Os instrumentos actuais são praticamente ineficazes.

As agressões ecológicas são imensas e gravíssimas, a humanidade está a correr grandes riscos, as sociedades em que vivemos são cada vez mais sociedades em risco. E infelizmente não se vê, pelo menos até agora, que as sucessivas conferências internacionais que têm vindo a alertar para esses perigos (desde a conferência do Rio de Janeiro até à recente conferência de Quioto) tenham avançado decisivamente neste domínio.

A explosão demográfica é outro dos fenómenos mais preocupantes do nosso tempo. A essa explosão está, aliás, associada a pobreza, a qual, paradoxalmente, está a crescer em relação directa com o significativo aumento da riqueza. A pobreza crescente atinge as pessoas e as sociedades, dividindo-as entre si. A pobreza divide os pobres dos ricos e as nações mais desenvolvidas e poderosas das nações subdesenvolvidas. Mesmo dentro das nações mais ricas, são cada vez menos os que têm acesso à riqueza e cada vez mais os que não têm acesso a ela, multiplicando-se os fenómenos de exclusão social, de marginalização e de criminalidade organizada a nível internacional. Assistimos também ao regresso de certas formas de comportamento que julgaríamos ultrapassadas por um suposto «triunfo universal da democracia», como por exemplo o fundamentalismo, o fanatismo, o terrorismo e outras formas extremas de desespero.

A ciência ou, melhor dito, as ciências proporcionam hoje os meios para ajudar a resolver muitos dos problemas do nosso tempo - a começar pelo problema da fome e da pobreza extrema. Mas a verdade é que tais meios não são mobilizados para esses fins. E é legítimo perguntar: porquê? Serão, naturalmente, múltiplas as respostas. Mas uma das mais óbvias é a que nos diz que a organização das sociedades contemporâneas não é suficientemente adequada e perfeita para dar resposta a todas essas situações. Quando se fala de mundialização e se diz que estamos a assistir 
à globalização das economias, dos conhecimentos e das informações, esse é um facto real e inevitável, mas é preciso dizer também que todos os grandes problemas que referi - e que vamos legar às novas gerações, ao novo século e ao novo milénio - só poderão ter respostas e soluções globais, isto é, no plano mundial e não no quadro estritamente nacional. Daí que a globalização esteja a provocar a erosão e a corroer uma instituição cujo valor era quase absoluto no século XIX e que hoje é cada vez mais relativo, ou seja, o valor do estado-nação.

Como lutar, então, por um mundo melhor? Como lutar pela resolução de todos os grandes problemas com que as sociedades contemporâneas e os diversos ramos da ciência hoje nos interpelam? Sabemos bem, pelo que foi a experiência histórica deste século XX, quase a terminar, que a violência não é a resposta adequada, porque a violência gera sempre mais violência. A ideia revolucionária e romântica dos «amanhãs que cantam» - segundo a qual a «grande revolução» venceria e iria resolver, num amanhã radioso, como que por milagre, todos os problemas - sabemos no que deu. Sabemos que os verdadeiros problemas se levantam quando as ordens e os sistemas injustos são destruídos - e não antes. É depois dos actos libertadores, como por exemplo o 25 de Abril, que os problemas se tornam mais complexos e exigem mais esforço e responsabilidade.

Numa sociedade de informação, aberta e global, como aquela em que estamos a viver, é no quadro da progressiva universalização da democracia pluralista, por mais formal que ela seja considerada, que devemos lutar pela resolução dos problemas. E é nesse quadro que a cidadania assume um valor e um papel fundamentais. É através de uma cidadania cada vez mais consciente e activa, cada vez mais participativa e informada no plano científico, que as sociedades devem encontrar as respostas para a construção de um futuro mais digno e melhor para a humanidade. Ora, essa cidadania - que não pode ser apenas concebida no âmbito nacional, tem de ser também uma cidadania sem fronteiras - só pode ser fruto da educação e da ciência consideradas como verdadeiros pilares da organização de uma sociedade moderna, livre e plural. 
(Página deixada propositadamente em branco) 
 \\ A palavra "fronteiras" pode ser tomada em} diferentes sentidos. Pode referir-se aos limites, necessariamente provisórios, entre o conhecido e o desconhecido, ou aos limites entre o possivel e o impossivel, e, dentro do possivel, entre o desejável e 0 indesejável. Fronteiras podem também ser as delimitações, nem sempre nítidas, entre ciência e não-ciência, e dentro da ciência, entre as várias disciplinas. Quais são então as fronteiras da ciência?

Neste livro, a resposta a esta pergunta é dada, segundo as mais diferentes perspectivas, por um conjunto notável de personalidades, cientistas ou não, entre as quais se contam três Prémios Nobel.

Rui Fausto, Carlos fiolhais e JoÃo Fillipe Queiró são, respectivamente, professores de Química, Física e Matemática na Faculdade de Ciências e Tecnologia da Universidade de Coimbra. 